\title{
Reversible airways obstruction and interstitial pneumonitis due to acetic acid
}

\author{
KG RAJAN, BH DAVIES \\ From the Asthma Research Unit, Sully Hospital, Nr Penarth, South Glamorgan, UK
}

Industrial exposure to gases and fumes may produce a wide variety of respiratory damage including tracheobronchial inflammation and parenchymal damage. ${ }^{1}$ Tracheobronchial inflammation is reported, particularly after exposure to chlorine, ammonia, and sulphur dioxide. Interstitial pneumonitis has been associated with the inhalation of oxides of nitrogen, ${ }^{2}$ cadmium, ${ }^{3}$ manganese,${ }^{4}$ mercury, ${ }^{5}$ and resins containing trimellitic anhydride. ${ }^{6}$

We report a patient who developed both reversible airways obstruction and steroid responsive interstitial pneumonitis after accidental exposure to glacial acetic acid.

\section{Case report}

A male 37 year old maintenance fitter was exposed to a blow back of glacial acetic acid in a petrochemical works. Immediate aid was given but first degree burns of the face and arms quickly occurred. Over the next seven days he developed progressive exertional dyspnoea, limiting him to walking quietly on the flat. He had no prior respiratory illness, was a non-smoker, and there was no family history of asthma. On examination there was evidence of burns to the face and arms and inspiratory basal crackles. Routine haematology and biochemistry test results were normal. Chest radiograph showed patchy bilateral reticulonodular infliltration dominantly of the bases. No improvement occurred over the next three months and on referral to our unit he was found to be moderately dyspnoeic at rest and there were persistent extensive crackles in the basal areas of his lungs with bilateral scattered wheeze. The chest radiograph showed little change and physiology showed FEV, 1.65 (pred 3.69) and FVC 2.0 (pred 4.62) litres. TLCo was $18 \mathrm{ml} / \mathrm{min} / \mathrm{mm} \mathrm{Hg}$. Bronchoscopy showed widespread bronchial inflammatory changes and bronchopulmonary lavage showed macrophages $3.28 \times 10^{6}$, lymphocytes $1.68 \times 10^{6}$, and red blood cell count $1.41 \times 10^{7}$. These results show a doubling of macrophages and a tenfold increase in lymphocytes which were $34 \%$ of the total inflammatory cells. Transbronchial biopsy showed a diffuse, moderate mainly mononuclear, interstitial pneumonitis. The patient was treated with high dose nebulised bronchodilators and corticosteroids. There was a prompt and sustained improvement in spirometry and clearing of his chest radiograph. Progress has been maintained at 18 months.

\section{Discussion}

Glacial acetic acid is highly irritant to the skin and mucous membrane and inhalation of the vapour results in acute tracheobronchitis. The long term effect is unknown as the vapour becomes intolerable to inhale, long before dangerous concentrations are reached, making the hazard negligible under normal conditions. ${ }^{7}$ Our patient's accident happened while he was disconnecting a pressurised pump containing hot glacial acetic acid for overhaul. It fractured coating his face and he inhaled a large cloud of hot acetic acid as it vapourised.

Diffuse alveolar damage results when a noxious agent damages the bronchoalveolar lining cells and endothelial cells of the lung. ${ }^{8}$ The outcome of the reaction is dependent on the intensity and duration of exposure and varies from death in acute phase to resolution or interstitial fibrosis or obliterative bronchiolitis, or both, Matthes et al found diffuse tracheobronchitis and acute pneumonitis in their fatal cases of mercury vapour inhalation' and Beton et al reported congestion of the lungs with severe haemorrhagic pneumonitis in five cases of acute cadmium fume poisoning. ${ }^{10}$

The course of the disease varies with the intensity of exposure, chemical nature of the agent, and the interval between the exposure and start of treatment. ${ }^{45}$ Apart from general supportive measures, oxygen, antibiotics for secondary infection, bronchodilators, and steroids have been recommended in acute pneumonitis with varying degree of response. Our patient showed a satisfactory response to steroids and 
the lymphocytic dominance of his bronchopulmonary lavage cells suggests that the pneumonitis in the chronic phase may have an immunological basis.

We thank Mr K Jones for B-P lavage analysis and Mrs $\mathrm{J}$ Holmes for typing the manuscript.

\section{References}

1 Morgan WKC, Seaton A. Occupational lung diseases. London: W B Saunders Company, 1984:609-42.

2 Jones GR, Proudfoot AT, Hall JJ. Pulmonary effects of acute exposure to nitrous fumes. Thorax 1973;28:61-5.

3 Smith TJ, Petty TL, Reading JC, et al. Pulmonary effects of chronic exposure to airborne cadmium. Am Rev Respir Dis 1976;114:161-9.
4 Lloyd-Davies TA, Harding HE. Manganese pneumonitis. Br J Ing Med 1946;3:111-35.

5 Seaton A, Bishop CM. Acute mercury pneumonitis. Br J Ind M层 1978;35:258-65.

6 Herbert FA, Orford R. Pul haemorrhage and oedema due to inhalation of resins containing trimellitic anhydride. Che 1979;76:546-51.

7 Guide to the safe handling of chemicals, acetic acid (Data sheet 202.) BP Chemicals Ltd. ("In house")

8 Gibbs AR, Seal RME, Wagner JC. Pathological reactions of the lung to dust. In: Morgan WKC, Seaton A, eds. Occupation lung diseases. Philadelphia: WB Saunders, 1984:129-62.

9 Matthes FT, Kirschner R, Yow MD, Brennan JC. Acute poisof ing associated with inhalation of mercury vapour. Pediatrics 1958;22:675-88.

10 Beton DC, Andrews GS, Davies HJ, et al. Acute cadmium fumet poisoning: five cases with one death from renal necrosis. $\mathrm{Br} J$ Ind Med 1966;23:292-301. 